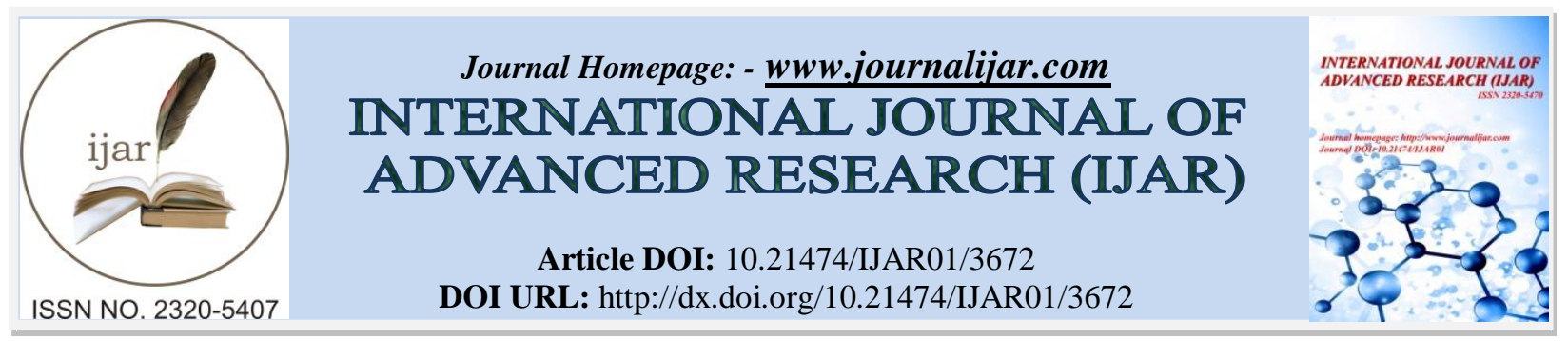

RESEARCH ARTICLE

\title{
STEM CELL REGENERATIVE THERAPY IN ORAL AND MAXILLOFACIAL REGION: A SYSTEMATIC REVIEW.
}

\section{Dr. Saraswathi Gopal. K and Dr. Padma. M.}

1. MDS Professor and Head, Dept of Oral Medicine and Radiology, Meenakshi Ammal Dental College and Hospital, Chennai, India.

2. Post Graduate student, Dept of Oral Medicine and Radiology, Meenakshi Ammal Dental College and Hospital, Chennai, India.

\section{Manuscript Info}

-

Manuscript History

Received: 11 January 2017

Final Accepted: 09 February 2017

Published: March 2017

Key words:-

stem cells; regeneration ; embryonic stem cells; dental pulp; stem cell therapy; regenerative dentistry; oral mucosal lesions; cancer management.

\section{Abstract}

In the modern era, where biology and biotechnology have replaced the chemistry, we are exploring "biological solutions to biological problems." The breakthrough of stem cells has produced new possibilities in the regeneration of different organs and tissues. The scope of application of stem cells in dentistry is vast and includes continued root formation, in pulp/dentin tissue regeneration, in replantation and transplantation, and reconstruction of the periodontium, in cancer management and research. In few years plenty of studies have been conceded which showed that stem cells and tissue engineering are giving rise to a separate branch termed "Regenerative Dentistry" that will have its own position in future dental practice. This article provides an insight into the various aspects of stem cells therapies in oral mucosal lesions and its future perspectives.

Copy Right, IJAR, 2017,. All rights reserved.

\begin{abstract}
Abbreviations:-
BMSC'S -Bone marrow stem cells; MSC'S- Mesenchymal stem cells; ADSC's- Adipose derived stem cells ; DPSC's- Dental pulp stem cells ; SHED- Stem Cells from Exfoliated Deciduous teeth; PDLSC's- Periodontal ligament stem cells; SCAP- Stem cells from Apical papilla; DFPC's- Dental Follicle Precursor Cells; ESC'sEmbryonic stem cells; IPSC's- Induced Pluripotent Stem Cells; CSC's- Cancer Stem Cells; PLGA- Poly Lactic co glycolic acid; PGA- Poly Glycolic Acid
\end{abstract}

\section{Introduction:-}

Stem cells are the precursors of the body tissue which are undifferentiated biological cells that can differentiate into specialized cells and can divide (through mitosis) to produce extra stem cells. ${ }^{(1,2)}$ They are also defined as immature or undifferentiated cells that are capable of generating daughter cells identical to themselves or of differentiating into diverse cellular phenotypes. These cells are originated in multicellular organisms ${ }^{(3,4)}$. Human dental tissues have a limited potential to regenerate but the discovery of dental stem cells have developed new and surprising scenario in regenerative dentistry.

Corresponding Author:- Dr. Saraswathi Gopal. K. 


\section{History Of Stem Cells:-}

Stem cells also known as "progenitor or precursor" cells and are clonogenic cells capable of both self-renewal and multi-lineage differentiation. In 1868 the term "stem cell" for the first time appeared in the works of German biologist Haeckel ${ }^{(4,5)}$. Wilson coined the term stem cell ${ }^{(5)}$. In 1908 Russian Histologist Alexander Maksimov postulated existence of hematopoietic stem cells at congress of hematologic society in Berlin ${ }^{(6)}$. Then the term "stem cell" was proposed for scientific use.

\section{Stem Cell Properties:-}

A classic stem cell should possess two properties namely self renewal and potency ${ }^{7,8,9}$.

- Self-renewal is the capacity of the cell to undergo numerous cycles of cell division maintaining the undifferentiated state. An ideal stem cell should have the capacity of self renewal (the ability of the cell to proliferate to about $40-60$ population doublings).

- Potency means the differentiation capacity of the stem cells.

\section{Classification Of Stem Cells ${ }^{(10,11):-}$}

There are different types of stem cells that are usually considered for their potential use in research. They can be classified on the basis of the following:

1. The extent to which they can differentiate into different cell types.

2. Source of stem cells.

\section{Extent to which they can Differentiate:-}

a. Totipotent cells: These stem cells have the potential to differentiate into any kind of cell in the body.

b. Pluripotent cells: These are true stem cells, with the potential to differentiate into any differentiated cells in the body, except the cells of placenta or other supporting tissues of the uterus.

c. Multipotent cells: These are true stem cells, but only differentiate into a limited number of cell types, e.g. the bone marrow contains multipotent stem cells that give rise to all the cells of the blood but not to other types of cells. Multipotent stem cells are of three major types - ectodermal (skin and nerves), mesodermal or mesenchymal (bone, cartilage, muscle and adipose tissue) and endodermal (intestines and other organs).

\section{On the Basis of Source ${ }^{(12,13):-}$}

a. Embryonic stem cells

b. Embryonic germ cells

c. Adult stem cells

d. Induced pluripotent stem cells

a. Embryonic stem cells ${ }^{(14)}$ :-

Embryonic stem cells (ESCs) are derived from 4 to 5day old embryo, (early-stage embryo, 4-5 days old, consist of 50-150 cells) or earlier morula-stage embryo. At this stage, the embryos are spherical and are known as blastocysts. Each blastocyst consists of 50 to 150 cells and includes three structures: an outer layer of cells, a fluid filled cavity and a group of about 30 pluripotent cells at one end of the cavity called the inner cell mass( Figure 1) .

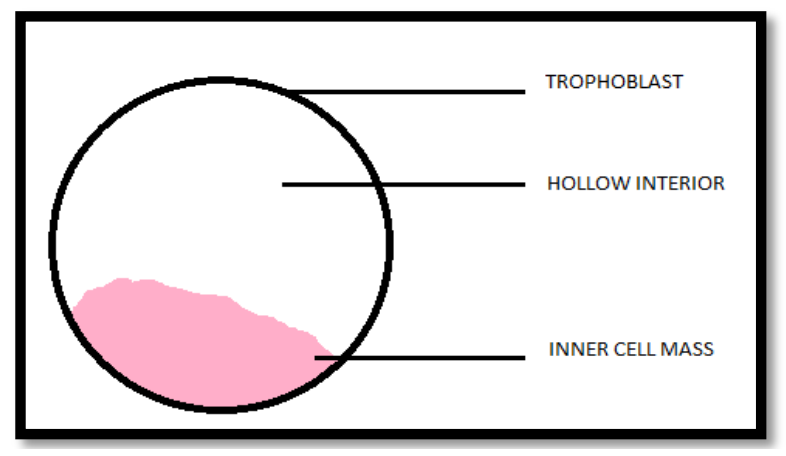

Figure 1:- Embryonic stem cells from blastocyst . COURTESY: K. Saraswathi Gopal et al : Stem cell and the regenerative dentist: International Journal of Contemporary Dental and Medical Reviews (2015) 
b. Embryonic germ cells (or foetal germ cells):- Embryonic germ cells are pluripotent stem cells derived from the so-called primordial germ cells, which are the cells that give rise to the gametes (sperm and eggs) in adults. These can be isolated from the precursor to the gonads in aborted tissues.

c. Adult Stem Cells:- Adult stem cells are characterised as haematopoietic or mesenchymal . Hematopoietic stem cells are capable of forming all types of white blood cells and red cells. Sources of Haematopoeitic stem cells are Umbilical cord blood, Umbilical cord, bone marrow and peripheral blood. Haematopoietic stem cells have been used to treat blood cancers such as leukaemia and other blood disorders. Mesenchymal are capable of forming a wide variety of connective tissues such as bone, muscle, cartilage, fat, tendons-but not internal organs or skin , Sources of Non-haematopoietic Stem Cells or Mesenchymal Stem Cells are adipose tissue, bone marrow and almost all body tissues including the pulp tissue of the teeth ${ }^{(13)}$.

Bone marrow ${ }^{(14,15)}$ :- Bone marrow stem cells (BMSCs) can be harvested from sternum or iliac crest. It is composed of both hematopoietic stem cells and mesenchymal stem cells (MSCs). The advantage of bone marrow is that it has a larger volume of stem cells and can be differentiated in to wide variety of cells. Isolation of BMSCs can be carried out only under general anesthesia. Bone marrow contains both types of stem cells and has been most extensively researched.

Adipose tissue $^{(8,16)}$ :- They can be harvested from the lipectomy or liposuction aspirate. Adipose derived stem cells (ADSCs) contain a group of pluripotent mesenchymal stem cells. Advantage of adipose tissue is that it is easily accessible and abundant in many individuals.

\section{d. Induced pluripotent stem cells:- ${ }^{(17)}$}

Induced pluripotent stem cells (iPSCs) are adult cells that have been genetically reprogrammed to an embryonic stem cell-like state by being forced to express genes and factors important for maintaining the defining properties of embryonic stem cells. They express stem cell markers also and are capable of generating cells characteristic of all three germ layers. iPSCs may prove to be useful tools for drug development and modeling of diseases and in transplantation medicine. In this evolving concept 3-4 genes found in the stem cells are transferred into the donor cells using appropriate vectors. The stem cells thus derived by culturing will have properties almost like embryonic stem cells. This path breaking discovery may have a major role in future stem cell therapy.

\section{Source Of Stem Cells From Dental Tissues ${ }^{(18,19):-}$}

Stem cells from oral and maxillofacial region predominantly contain mesenchymal stem cells. Deciduous teeth, wisdom teeth and tooth extracted for orthodontic treatment are the major sources of dental tissue. In oral and maxillofacial area different types of dental stem cells were isolated and characterized (Figure : 2). They include

- Dental pulp stem cells (DPSCs)

- Stem cells from exfoliated deciduous teeth (SHED)

- Periodontal ligament stem cells (PDLSCs)

- Stem cells from apical papilla (SCAP)

- Dental follicle progenitor cells (DFPCs)

Dental pulp stem cells (DPSCs) were successfully isolated by Gronthos et $\mathrm{al}^{(18)}$, in 2000 . They were able to demonstrate odontoblast like cells from DPSCs producing ectopic dentin in the immunocompromized mice.

Stem cells from exfoliated deciduous teeth (SHED) ${ }^{(19)}$ were identified to be cells of higher proliferation rate, with increased population doublings, immature multipotent clonogenic cells isolated from deciduous teeth that can differentiate into several cell types.

Periodontal ligament stem cells (PDLSCs) were isolated from periodontal ligament of 25 human third molars by Seo BM et al in $2004^{(20)}$. They demonstrated cementoid cells, adipocytes when transplanted into immunocompromized rodents.

Stem cells from apical papilla (SCAP) Sonoyama et al in $2008^{(21)}$ isolated mesenchymal stem cells from apical papilla which are capable of forming odontoblast like cells in vivo. 
Dental follicle progenitor cells (DFPCs) Morsczeck C et al in $2005^{(22)}$ obtained stem cells from dental follicle which can form cementoblasts, periodontal ligament cells and osteoblasts.

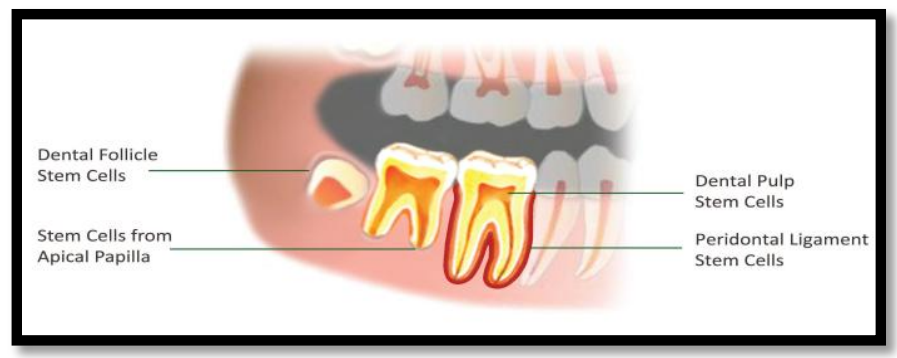

Figure 2:- Stem cells of dental origin

\section{Dental Stem Cells Advantages ${ }^{(6,24)}$ :-}

The advantages of stem cells from oral and maxillofacial region is that

1. Have high plasticity.

2. It can be cryopreserved for longer period.

3. It showed good interaction with scaffold and growth factors.

4. The dental pulp stem cells will be better fitting tool due to easy surgical access, the very low morbidity of the anatomical site.

\section{Stem Cells Storage And Transport ${ }^{(24,25)}$ :-}

Tissue samples containing stem cells are placed in a screw top vial containing Hypothermosol, mesencult basal medium or phosphate-buffered saline media, which nourishes it during transport. The sample should reach the processing storage facility before 40 hours. In the laboratory the samples were trypsinized and cryopreserved at $-150^{\circ} \mathrm{C}$ to yield colonies of stem cells. The required cell type can be manipulated by utilizing right inductive signals and appropriate growth factors to the stem cells.

\section{Stem Cell Application In Oral Diseases:-}

Clinical applications of dental stem cells will continue to emerge in the near term and longer term. Currently dental stem cell research focuses on regeneration of dentine, pulp and teeth, alveolar bone, regeneration of periodontal ligament, and various other applications of mesenchymal and hematopoietic stem cells in repair of craniofacial defects, oral mucosal lesions and salivary gland regeneration after radiation therapy.

\section{Regeneration of teeth ${ }^{(25,26)}$ :-}

Tooth regeneration represents a new era in dentistry as the concepts of repair is being shifted to regeneration. Regenerative dentistry restores a tissue defect to its original form and function by biological substitutes. Dental tissue stem cells/ progenitor cells can differentiate into dental cell lineages, and are used to regenerate some dental tissues in the treatment of tooth defects and tooth loss. Research focuses on whole tooth regeneration using a strategy of transplanting artificial tooth germ and allowing it to develop in the adult oral environment. Two means of regenerating teeth include conventional tissue engineering, in which the application of cells in a carrier material in vitro under the influence of a stimulus leads to tissue regeneration. The second process of tooth regeneration is using dental epithelium and mesenchymal cells $\mathbf{s}^{(27,28)}$ in vivo after direct implantation, which is based on knowledge of embryogenesis and physiological tooth development during childhood.

Handa K (2002) ${ }^{(29)}$ isolated progenitor cells from bovine dental follicles. In invitro conditions these cells formed clusters of spheroid like cells and in invivo conditions, cementum matrix formation took place by these cultured dental follicle cells. Gronthoset al 2002 ${ }^{(25)}$ demonstrated both in vivo and in vitro in animals that dental pulp stem cells (DPSCs) were able of forming ectopic dentin and related pulp tissue ${ }^{(25)}$ Batouli et al. 2003 ${ }^{(30)}$ demonstrated the capacity of dental pulp stem cells to form a dentin pulp-like complex by transplanting them in immunocompromised mice. After 16 weeks, the pulp-like tissue contained a fibrous connective tissue, blood vessels, and odontoblasts associated with newly formed dentin indicating the possibility of using those stem cells for the repair of injured dental structures. Duailibi et al. $2004^{(31)}$, in their studies were able to form tooth from single cell suspensions of cultured rat tooth bud cells. They confirmed bioengineered rat teeth grown in 12 weeks with Poly Lactic co glycolic 
acid (PLGA) and Poly glycolic acid (PGA) scaffold. Honda et al 2005 $5^{(32)}$ developed tissue engineered teeth, when implanted into omentum of rat utilizing porcine tooth bud cells and PGA fiber engage scaffold that reminds of the model of odontogenesis. Young et al 2005 ${ }^{(33)}$ using porcine tooth bud cells, PLGA and PGA scaffolds produced a crossbreed tooth bone for the cure of tooth loss beside with alveolar bone resorption. Huang et al $2008^{(34)}$ in his review article summarized new protocol for endodontically involved immature permanent teeth in which minimal instrumentation was done in it followed by disinfection with triple antibiotic paste. Treated tooth is coated with mineral trioxide aggregate (MTA) and filled with glass ionomer cement. Periodical observation was done to ascertain root maturation.

\section{Periodontal regeneration:-}

Recently new techniques of cell transplantation have been developed to regenerate periodontium using Periodontal ligament cells (PDLCs) isolated from extracted human teeth and Dental follicle stem cells (DFSCs) which could become an alternative cell source for periodontal regeneration therapy. When transplanted into immunocompromised mice, PDLCs have shown to regenerate collagen fibers and cementum/periodontal ligamentlike structures. Periodontium can also be regenerated by culturing of periosteum, non-dental stem cells such as bone marrow mesenchymal stem cells, and adipose-derived stem cells. Studies have shown that grafted autologous cultured cell membrane derived from periosteum into a surgically created class III furcation defect in dogs, lead to the formation of cementum, periodontal ligament-like tissues, and alveolar bone in 3 months after the grafting procedure. Another research reported a treatment using cells derived from periosteum in human periodontal disease by Kawaguchi et al2004 ${ }^{(35)}$. It is also confirmed by Hasegawa et al 2005, that periodontal defects can be managed by reimplantation of these cells ${ }^{(36) . ~ A u t o l o g o u s ~ m e s e n c h y m a l ~ s t e m ~ c e l l s ~ f r o m ~ i l i a c ~ c r e s t ~ i n ~ c o m b i n a t i o n ~ w i t h ~}$ platelet rich plasma from peripheral blood was used for periodontal regeneration. Significant closure of bone defect and improvement of attachment level was observed after one year follow up. It also showed good healing and regeneration of interdental papilla ${ }^{(37)}$ Nagatomo et al2006 ${ }^{(38)}$ in their experimental studies found that PDL cells having stem cell properties can regenerate periodontium. Transplantation of PDL derived cells into animal models were shown to regenerate periodontal tissue. Iwata et al2009 ${ }^{(39)}$ harvested and expanded primary canine PDL cells in vitro and also made into transplantable constructs containing Poly glycolic acid (PGA) Scaffold and PDL cell sheets. The transplantable constructs in combination with porous tricalcium phosphate (b-TCP) induced regeneration of periodontal structures, including alveolar bone, cementum, and periodontal fibers. Liu et al2008 regenerated periodontal tissue in miniature swine using scaffolds seeded with periodontal ligament derived stem cells ${ }^{(40)}$. PDLSCs can differentiate into cells that can colonize on biocompatible scaffold, suggesting an easy and efficient autologous source of stem cells for regeneration of dental tissues ${ }^{(41)}$ Marie MK et al 2009in their experimental on goat was able to regenerate periodontal tissues around titanium implant using autologous bone marrow stem cells with scaffold ${ }^{(42)}$

\section{Repair of craniofacial defects:-}

Craniofacial defects results from post-cancer ablative surgery, craniofacial osseous deficiencies can also arise from infection, trauma, congenital malformations and progressively deforming skeletal diseases. Although autologous bone graft is considered the best option, it has the limitation of donor sites. Use of skeletal or dental stem cells can be used in future to repair craniofacial region and may provide a promising alternative approach for reconstruction of craniofacial defects. Lagenbach et al2010 ${ }^{(43)}$ in their in vitro studies used microspheres (scaffold free tissue construct) to close the bone defects. They found osteogenically differentiated microspheres with outgrowing cells can be used to fill up bone defects. This new procedure has added advantage of permitting the transplantation of more cells and better integrity compared with cell suspensions or gels ${ }^{(44)}$. Degenerative bone diseases including TMJ defects can be bioengineered with stem cells. Cells from various sources like articular cartilage cells, fibroblasts, mesenchymal stem cells have been used to reconstruct $\mathrm{TMJ}^{(45) \text {. }}$ Bone tissue engineering endeavours to repair large bone losses using three dimensional scaffolds to deliver vital cells to the defective site.

\section{Stem Cell Therapy in Oral Mucosal Lesions:-}

Among oral mucosal lesions, stem cell research is presently focused on the treatment of certain lesions only. These oral mucosal lesions are:

Ulcerative lesions: oral ulcers and wounds, oral mucositis, pemphigus vulgaris

Potentially malignant disorders: Oral submucous fibrosis (OSMF), Oral lichen planus (OLP).

Malignant lesions: oral carcinoma. 
The main mechanism behind the use of stem cells in these lesions is discussed in detail. Oral ulcers and wound healing ${ }^{(46)}$ :-

Optimum healing of a cutaneous wound requires a good integration of the complex biological and molecular events of cell migration and proliferation and extracellular matrix deposition, angiogenesis and remodeling. Large wounds take a long time to heal, and defective healing leaves behind unacceptable scars and strictures.

Bone marrow-derived mesenchymal stem cells (BM-MSCs) are self-renewing, expandable stem cells and are able to differentiate into adipocytes, osteoblasts, and chondrocytes. These are used possess the ability to engraft at the site of injury and promote tissue regeneration and wound healing through synergistic downregulation of proinflammatory cytokines and increased production of soluble factors with antioxidant, antiapoptotic, and proangiogenic properties.

In oral wounds, they exhibit increased re-epithelialization, cellularity, intracellular matrix formation and neoangiogenesis, thereby accelerate wound healing. Hence, MSC therapy can be a promising therapeutic modality for oral ulcers and wounds. El-Menoufy et al $2010^{(47)}$. Submucosally injected autologous Bone MarrowMesenchymal Stem Cells suspended in phosphate buffered saline around formocresol induced oral ulcers in dogs. There was increased expression of both collagen and vascular endothelial growth factor (VEGF) genes in Mesenchymal Stem Cells-treated ulcers compared with controls. Similar results were seen by Aziz Aly et al $2012 .^{(48)}$ in a study on formocresol induced oral ulcers in dogs using Bone Marrow and adipose-derived stem cells. Hence He concluded Mesenchymal Stem Cells transplantation may help to accelerate the healing of oral ulcers [Figure 3].

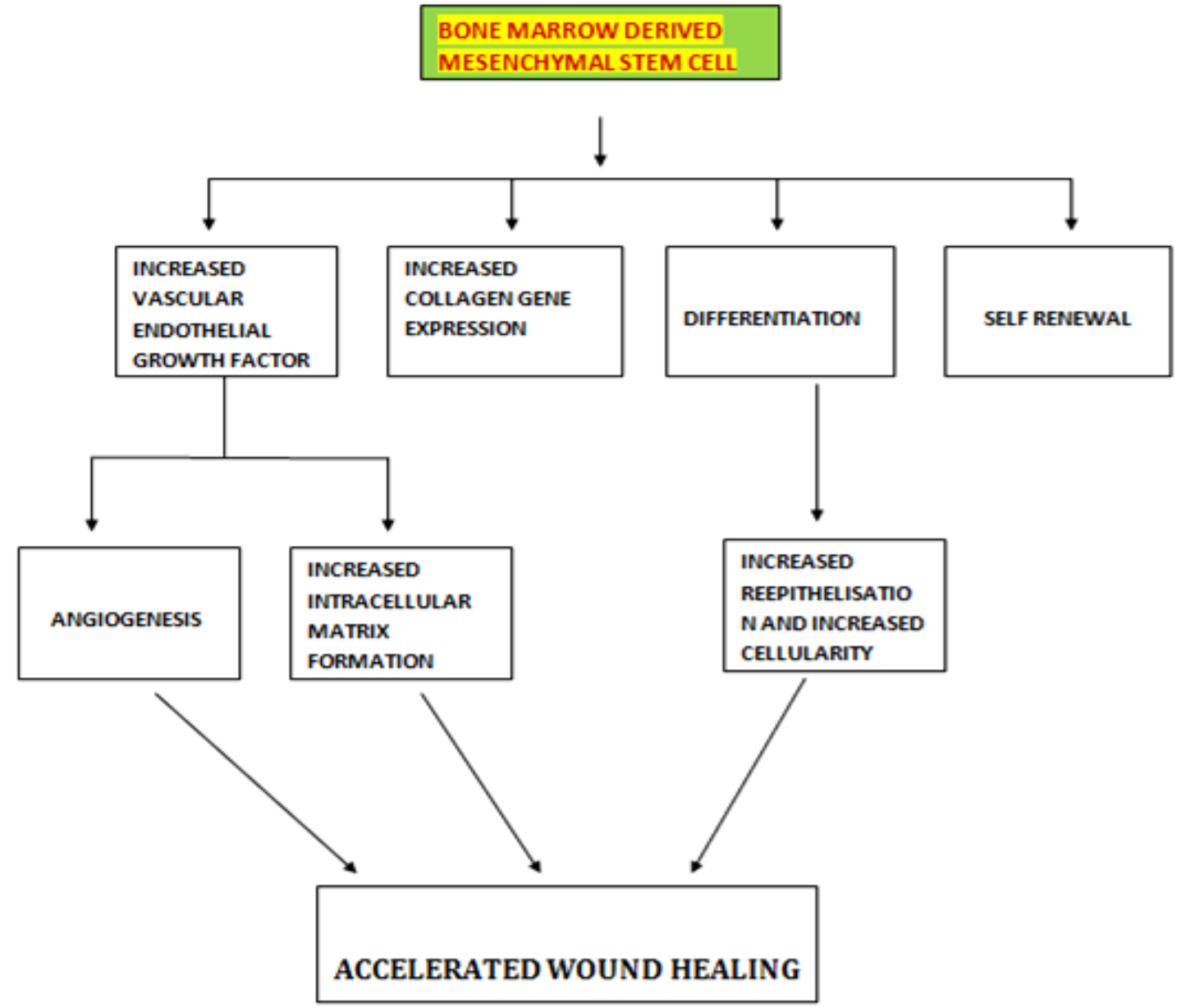

Figure 3:- Role of mesenchymal stem cells in wound healing Courtesy : Journal of Pharmacy \& Bioallied Sciences : Jan-Mar 2015; 7 (1): 2-8 


\section{Oral mucositis:-}

Oral mucositis is one of the most debilitating side effects which occur with chemo or radiotherapy. Management of mucositis is fairly symptomatic. Presently mesenchymal stem cells have been explored in its management by virtue of their immunomodulatory, anti inflammatory functions as well as regenerative properties. Their therapeutic efficacy can further be increased by transgenic approach or preconditioning them with certain factors like proinflammatory cytokines.

Zhang et al 2012.(49) injected spheroid Gingiva-Derived Mesenchymal Stem Cells (GMSCs) in mice with chemotherapy-induced oral mucositis and found that treatment with GMSCs decreased the severity and incidence of ulceration and restored the papillae structure, the lining, and thickness of the epithelial layer as compared with those of untreated disease group. The improved therapeutic benefits of spheroid-derived GMSCs may be attributed to their increased capabilities for engraftment and survival at the injury sites, trans-differentiation into epithelial cells, and preconditioning to hypoxic and oxidative challenges. Hence GMSCs could prove a sure shot therapy in oral mucositis following the cancer therapies.

\section{Pemphigus vulgaris:-}

Pemphigus vulgaris is a potentially life-threatening disease, primarily affects the mucous membranes of patients over the age of 50 years characterised by formation of autoantibodies, directed against desmosomal glycoproteins (dsg1, dsg3) present on the cell surface of the keratinocyte resulting in the formation of intraepithelial bullae and mucosal ulceration. The effective treatment of pemphigus vulgaris is long-term use of corticosteroids that itself has detrimental systemic complications. The immunomodulatory and antiinflammatory properties of stem cells can be utilized in the treatment of the condition.

In a research Vanikar et al.(2007) ${ }^{(50)}$ performed allogenic hematopoietic stem cell transplant (HSCT) with nonmyeloablative low-intensity conditioning in nine patients of Pemphigus vulgaris and found that the existing skin lesions started to regress within $24 \mathrm{~h}$ of stem cell treatment . In a similar study conducted by Vanikar et al in 2012 , consisted of clinical trial on patients with pemphigus vulgaris to evaluate the effects of allogenic Hematopoetic Stem cell Transplantation into thymus, bone marrow and peripheral circulation on central and peripheral arms; it was found that the recovery began within $24 \mathrm{~h}$ of HSCT and new lesions stopped after 6 months ${ }^{(51)}$. Stem cell therapy in pemphigus not only has shown promises in treatment but also brings about a shift towards non steroidal approach in autoimmune diseases. However the use of stem cell therapy for oral pemphigus is yet to be ascertained and needs new clinical trials.

\section{Stem Cell Therapy In Potentially Malignant Disorders:- Oral submucous fibrosis:-}

Oral submucous fibrosis is a chronic, insidious disease associated with both significant morbidity (including pain, reduced mouth opening) and an increased risk of malignancy. Various agents like Areca nut, gutkha, spices etc., are known to cause insult to oral mucosa by increasing cytokine production and release of reactive oxygen species; which in turn results in increased synthesis of collagen, decreased collagen breakdown, compromised vascularity and increased tissue oxidative stress, ultimately resulting in clinical OSMF ${ }^{(52)}$.

Stem cell therapy is primarily aimed at neoangiogenesis by releasing cytokines and growth factors (paracrine effect) ${ }^{(53)}$.This may result in increased free radical scavenging by antioxidants (either naturally occurring or extrageous). Neoangiogenesis may also facilitate the removal of senescent cells from the lesions by supplying more number of scavenging defense cells and reversal of hypoxia in the diseased tissue. Stem cell therapy may help to stimulate resident tissue stem cells to transform into new fibroblasts, which may help in the removal of disintegrated biochemically and morphologically altered collagen fibers( Figure 4)

Sankaranarayanan et al 2013. ${ }^{(54)}$ have demonstrated the effectiveness of stem cell treatment in OSMF patients by injecting $0.5-1 \mathrm{ml}$ of marrow-derived stem cell concentrate into labial and buccal mucosa and tongue under local anesthesia. They found reduction in blanching, decrease in the burning sensation while consuming spicy food, significant increase in the mouth opening and the results were found to be sustained in the follow-up period from 6 months to 5 years 


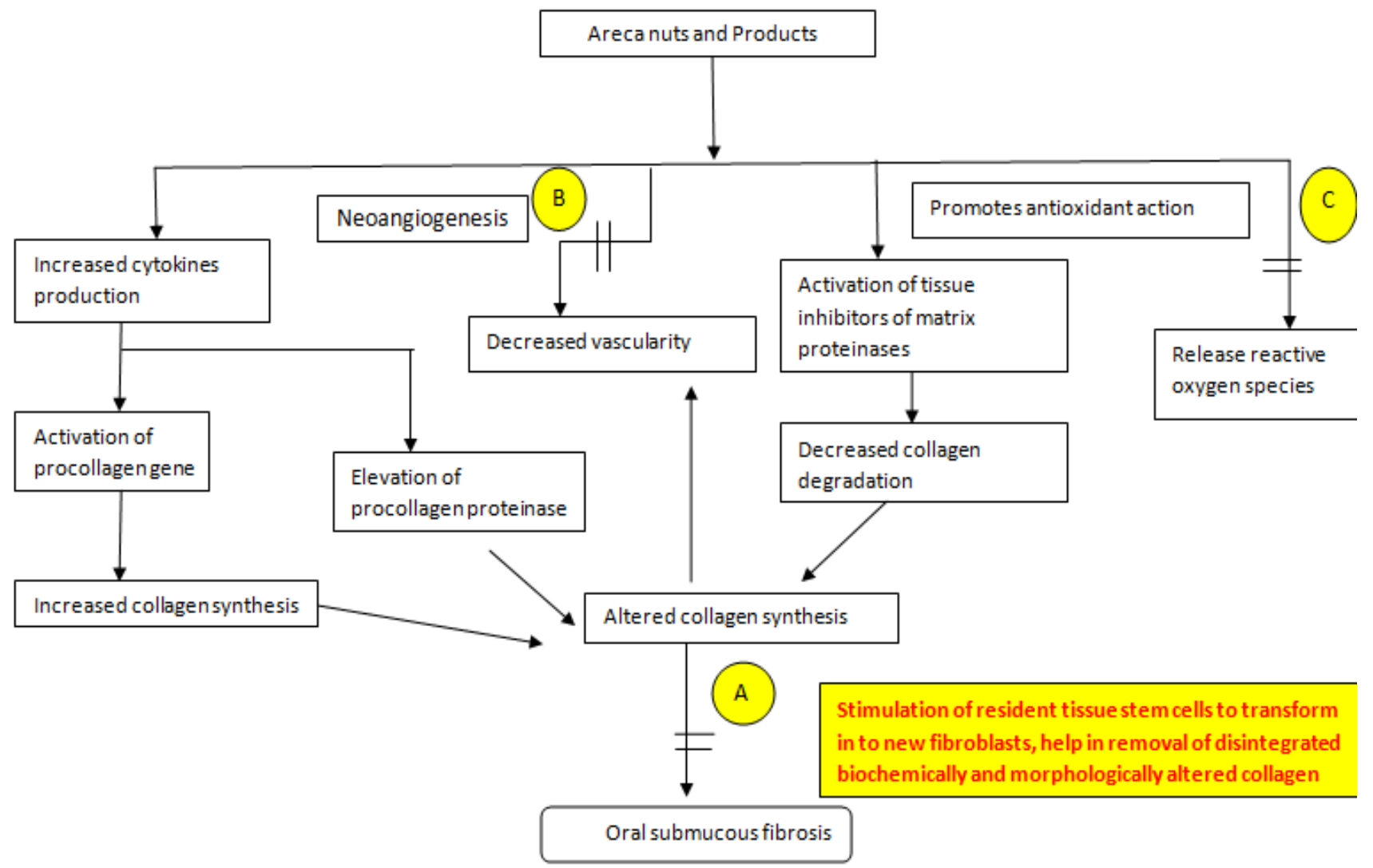

Figure 4:- Role of stem cell therapy in oral submucous fibrosis at various levels. (a) Removal of pathologically altered collagen and stimulation of healthy collagen. (b) Promoting neoangiogenesis. (c) Promoting antioxidant action. Courtesy: Journal of Pharmacy \& Bioallied Sciences : Jan-Mar 2015; 7 (1): 2-8

\section{Oral lichen planus:-}

Oral lichen planus (OLP) is a T cell-mediated, chronic mucocutaneous disease with uncertain etiopathogenesis. Various factors like stress, genetics, systemic diseases, drugs, dental restorative materials and viruses are known to cause the disease either by an antigen-specific mechanisms like activating cytotoxic T-cells and nonspecific mechanisms like mast cell degranulation and matrix metalloproteinase activation. Both of these cause the disruption of the basement membrane, which in turn triggers apoptosis of basal epithelial cells ${ }^{(55)}$. Recent advance in the treatment of lichen planus employ the use of immunomodulating agents such as tacrolimus which may treat the disease. In the past several years, studies have focussed on immunosuppressive properties of mesenchymal stem cells on various immune cell type as shown in figure 5. Based on these studies it is proposed that mesenchymal stem cells can be utilized to treat oral lichen planus via systemic infusion or local application ${ }^{(56,57)}$ 


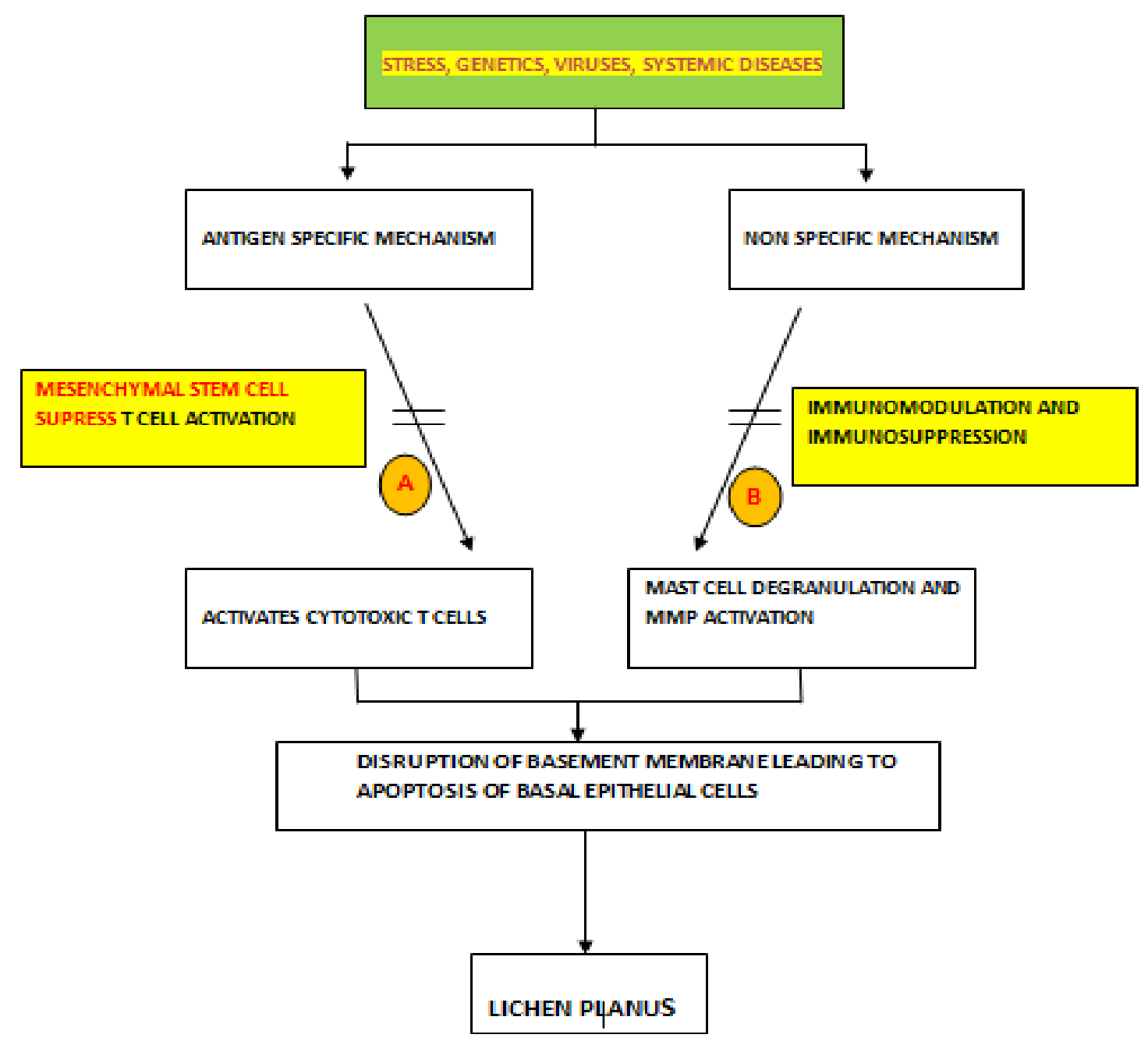

Figure 5:- Action of stem cells in modulation of immune response in oral lichen planus (shown at points A and B). Courtesy: Journal of Pharmacy \& Bioallied Sciences : Jan-Mar 2015; 7 (1): 2-8

\section{Malignant lesions:-}

\section{Oral carcinomas:-}

Surgery and external beam radiation has been the mainstay of treatment for head and neck squamous cell carcinomas. Studies in a wide variety of malignancies have demonstrated that a distinct subpopulation of tumor cells, termed Cancer stem cells (CSCs) ${ }^{(58)}$, contain the ability to undergo self-renewal and differentiation and hence have the ability to initiate tumorigenesis and support ongoing tumor growth. Stem cells here play a dual role-in carcinogenesis and in the development of possible new cancer treatment options in future. For past so many years stem cells have been used in the replenishment of blood and immune system damage during treatment of cancer by chemotherapy or radiotherapy.

Apart from their use in the immuno-reconstitution, the stem cells have been reported to contribute in the tissue regeneration as they have extraordinary capacity to regenerate and differentiate. Recently, a new model of carcinogenesis was suggested, which lead to the cancer stem cell hypothesis. According to this hypothesis, not all epithelial cells are capable of generating a tumour, and only long- surviving cells such as stem cells, can undergo the summative oncogenic alterations required for carcinogenesis ${ }^{(59.60)}$. 
The Mesenchymal stem cells (MSCs) have been used in the cell-based bone reconstruction following chemotherapy and surgery in malignancies like osteosarcoma and Ewing sarcoma ${ }^{(61)}$

Another important aspect of their use in cancer therapy is the use as delivery vehicles. Systematic delivery of drug or gene therapy has promising future but is currently limited by various factors such as immune detection, nonspecific accumulation in normal tissues and poor permeation. Stem cells can act as cell-based carriers that may target the desired site ${ }^{(62)}$. The recent concept of use of stem cells as delivery vehicles came from the fact that the tumors send out chemo-attractants such as Vascular endothelial growth factor (VEGF) to recruit mesenchymal stem cells (MSC) to form the supporting stroma of the tumor ${ }^{(63,64)}$. However, further work is required to understand the role of stem cells in cancer therapies, with the eventual goal of eliminating the residual disease and recurrence.

\section{Salivary gland regeneration after radiation therapy:-}

Radiation induced hyposalivation is a major problem in the treatment of head and neck cancer. Studies have shown that stem cell therapy may provide a means to reduce radiation-induced hyposalivation and improve the quality of life of patients. The ability of salivary gland tissue to regenerate after atrophy has provided knowledge about location and isolation of cell populations that contain salivary gland stem cells. It has been determined that within the ducts of salivary glands reside cells capable of proliferation and differentiation known as stem/ progenitor cell population. Application of specific growth factors to these cells induces differentiation into functional units ${ }^{(61)}$. Stem cells isolated from mouse salivary glands have shown to rescue saliva production in irradiated salivary glands.

Pringle et al in $2016^{(65)}$, showed engrafment and functional capabilities of human adult epithelial stem cells in salivary gland demonstatrd in vitro self renewal and differentiation into multilineage organoids. He also showed in vivo functionality, long term engrafment and functional restoration in Xenotransplantation model.

\section{Applications of dental stem cells in medical field:- ${ }^{(66)}$}

Dental pulp stem cells were proven to differentiate into functionally active neurons, and when implanted dental pulp stem cells induce endogenous axon guidance, suggesting their potential as cellular therapy for neuronal disorder. Thus based on these findings, stem cell research has hope in the field of medicine directed toward: brain damage, spinal cord injury, Parkinson's disease, Alzheimer's disease, multiple sclerosis and other neurological and neurodegenerative disorders. The Tissue regeneration concept hopes to repair heart damage, baldness, deafness, blindness, impaired vision, muscle damage, diabetes mellitus, etc. Stem cell research is a boon to drug research as the drug application can be directly given on to human cells, and this will provide more relevant data than testing on animal models.

\section{Conclusion:-}

Stem cell research in dentistry has given opportunity for dentists to assume a leading role not only in the treatment of dental pathosis and also in medical diseases. With the advances in the stem cell biology, dental stem cells will hopefully be able to correct cleft palate, periodontal defects, save injured teeth, jaw bones and most strikingly regenerate the entire teeth structures. Though certain studies have confirmed the effectiveness of stem cell therapy treatment in pemphigus vulgaris, potentially malignant disorder like Oral submucous fibrosis, the research is mainly confined to animal models in oral mucositis, cancer management and Lichenplanus, thus more human research trials are needed to ascertain the role of stem cells in their management. The evolution of more methods of stem cell therapy in the future will give simple, definitive and effective treatment of most of the oral mucosal diseases.

\section{Conflicts of interest: none}

\section{References:-}

1. Nedel F, Andre DA, Oliveira IO, Cordeiro MM, Casagrande L, Tarquinio SBC, Nor JE, Demarco FF. Stem Cells: Therapeutic Potential in Dentistry. J Contemp Dent Pract 2009 July; 4(10):090-096

2. Robey PG. Stem cells near the century mark. J Clin Invest. 2000;105:1489-91.[PubMed]

3. Gronthos S, Brahim J, Li W, Fisher LW, Cherman N, Boyde A, DenBesten P, Robey PG, Shi S. Stem Cell Properties of Human Dental Pulp Stem Cells. J Dent Res. 2002; 81(8):531-535.

4. Nadig RR. Stem cell therapy - Hype or hope? A review. J Conserv Dent. 2009;12:131-8. [PubMed]

5. Wilson EB. 1st ed. New York: Macmillan Company; 1996. The Cell in Development and Inheritance.

6. Ramta Bansal and Aditya Jain Current overview on dental stem cells applications in regenerative dentistry : Nat Sci Biol Med. 2015 Jan-Jun; 6(1): 29-34 
7. Chotkowski G. Stem Cells: Emerging Medical and Dental Therapies and the Dental Professional. Friends of hu-friedy academy. Oct 2008. Available from: http://www.friends of hu-friedy.com

8. Dr. P.E. Chandra Mouli, Dr. S.Manoj Kumar, Dr B.Senthil, Dr .S.Parthiban, Dr.R.Priya, Dr.R.Subha : Stem Cells in Dentistry- A Review./J. Pharm. Sci. \& Res. Vol.4(7), 2012, 1872 - 1876

9. Gardner RL. Stem cells: Potency, plasticity and public perception. J Anat 2002; 200:277-82

10. Sahana Srinath et al. Stem Cells And Its Relevance In Oral Cavity: A Review Of Literature: International Journal of Advances in Pediatric Dentistry, 2016;1(1):20-26.

11. Pera MF, Reubinoff B, Trounson A. Human embryonic stem cells. J Cell Sci. 2000;113(Pt 1):5-10.[PubMed]

12. Levenberg S, Zoldan J, Basevitch Y, Langer R. Endothelial potential of human embryonic stem cells.Blood. 2007;110:806-14 [PubMed]

13. Sumit Narang and Nidhi Sehgal Stem cells: A potential regenerative future in dentistry: Indian J Hum Genet. 2012 May-Aug; 18(2): 150-154.

14. K. Saraswathi Gopal, E. Madhubala : Stem cell and the regenerative dentist: International Journal of Contemporary Dental and Medical Reviews (2015), 7 Pages

15. Harender Singh, D. J. Bhaskar, Rahila Rehman, Chatainya Dev Jain , Mohsin Khan: Stem Cells: An Emerging Future in Dentistry : International Journal of Advanced Health Sciences June 2014 Vol 1 Issue 2

16. Zuk PA, Zhu M, Mizuno H, Huang J, Futrell JW, Katz AJ, et al. Multilineage cells from human adipose tissue: Implications for cell based therapies. Tissue Eng 2001;7: 211-28.

17. Takahashi K, Yamanaka S. Induction of pluripotent stem cells from mouse embryonic and adult fibroblast cultures by denied factors. Cell 2006; 126:663-76

18. Gronthos S, Mankani M, Brahim J, Robey PG, Shi S. Postnatal human dental pulp stem cells (DPSCs) in vitro and in vivo. Proc Natl Acad Sci U S A 2000; 97:13625-30.

19. Miura M, Gronthos S, Zhao M, Lu B, Fisher LW, Robey PG, et al. SHED: Stem cells from human exfoliated deciduous teeth. Proc Natl Acad Sci U S A 2003; 100:5807-12.

20. Seo BM, Miura M, Gronthos S, Bartold PM, Batouli S, Brahim J, et al. Investigation of multipotent postnatal stem cells from human periodontal ligament. Lancet 2004; 364:149-55.

21. Sonoyama W, Liu Y, Yamaza T, Tuan RS, Wang S, Shi S, et al. Characterization of the apical papilla and its residing stem cells from human immature permanent teeth: A pilot study. J Endod 2008; 34:166-71.

22. Morsczeck C, Götz W, Schierholz J, Zeilhofer F, Kühn U, Möhl C, et al. Isolation of precursor cells (PCs) from human dental follicle of wisdom teeth. Matrix Biol 2005; 24:155-65.

23. Yan M, Yu Y, Zhang G, Tang C, Yu J. A journey from dental pulp stem cells to a bio-tooth. Stem Cell Rev. 2011;7:161-71. [PubMed]

24. PM Sunil, R Manikandhan, MS Muthu, and S Abraham : Stem cell therapy in oral and maxillofacial region: An overview: J Oral Maxillofac Pathol. 2012 Jan-Apr; 16(1): 58-63.

25. Gronthos S, Brahim J, Li W, Fisher LW, Cherman N, Boyde A, et al. Stem cell properties of human dental pulp stem cells. J Dent Res. 2002;81:531-5. [PubMed]

26. Iohara K, Nakashima M, Ito M, Ishikawa M, Nakasima A, Akamine A. Dentin regeneration by dental pulp stem cell therapy with recombinant human bone morphogenetic protein 2. J Dent Res. 2004;83:590-5. [PubMed]

27. Langer RS, Vacanti JP. Tissue engineering: The Challenges ahead. Sci Am. 1999;280:86-9. [PubMed]

28. Nakao K, Tsuji T. Dental regenerative therapy: Stem cell transplantation and bioengineered tooth replacement. Jpn Dent Sci Rev. 2007;44:70-5.

29. Honda M J, Fong H, Iwatsuki S, Sumita Y, Sarikaya M: Tooth-forming potential in embryonic and postnatal tooth bud cells. Med Mol Morphol.41: 183-192 (2008)

30. Batouli S, Miura M, Brahim J, Tsutsui TW, Fisher LW, Gronthos S, Robey PG, Shi S. Comparison of Stem-cell-mediated Osteogenesis and Dentinogenesis. J Dent Res. 2003; 82(12):976-981.

31. Duailibi MT, Duailibi SE, Young CS, Bartlett JD, Vacanti JP, Yelick PC. Bioengineered teeth from cultured rat tooth bud cells. J Dent Res. 2004;83:523-8. [PubMed]

32. Honda MJ, Sumita Y, Kagami H, Ueda M. Histological and Immunohistochemical studies of tissue engineered odontogenesis. Arch Histol Cytol. 2005;68:89-101. [PubMed]

33. Young CS, Abukawa H, Asrican R, Ravens M, Troulis MJ, Kaban LB, et al. Tissue-engineered hybrid tooth and bone. Tissue Eng. 2005;11:1599-610. [PubMed]

34. Huang GT. A paradigm shift in endodontic management of immature teeth: Conservation of stem cells for regeneration. J Dent. 2008;36:379-86. [PubMed] 
35. Kawaguchi H, Hirachi A, Hasegawa N, Iwata T, Hamaguchi H, Shiba H, et al. Enhancement of periodontal tissue regeneration by transplantation of bone marrow mesenchymal stem cells. J Periodontol. 2004;75:1281-7. [PubMed]

36. Yamada Y, Ueda M, Hibi H, Baba S. A novel approach to periodontal tissue regeneration with mesenchymal stem cells and platelet-rich plasma using tissue engineering technology: A clinical case report. Int J Periodontics Restorative Dent. 2006;26:363-9. [PubMed]

37. Nakahara T, Nakamura T, Kobayashi E, Kuremoto K, Matsuno T, Tabata Y, et al. in situ tissue engineering of periodontal tissues by seeding with periodontal ligament-derived cells. Tissue Eng. 2004;10:537-44. [PubMed]

38. Nagatomo K, Komaki M, Sekiya I, Sakaguchi Y, Noguchi K, Oda S, et al. Stem cell properties of human periodontal ligament cells. J Periodontal Res. 2006;41:303-10. [PubMed]

39. Iwata T, Yamato M, Tsuchioka H, Takagi R, Mukobata S, Washio K, et al. Periodontal regeneration with multi-layered periodontal ligament-derived cell sheet in a canine model. Biomaterials. 2009;30:2716-23. [PubMed]

40. Liu Y, Zheng Y, Ding G, Fang D, Zhang C, Bartold PM, et al. Periodontal ligament stem cell-mediated treatment for periodontitis in miniature swine. Stem Cells. 2008;26:1065-73. [PubMed]

41. Trubiani O, Orsini G, Zini N, Di Iorio D, Piccirilli M, Piattelli A, et al. Regenerative potential of human periodontal ligament derived stem cells on three-dimensional biomaterials: A morphological report. J Biomed Mater Res A. 2008;87:986-93. [PubMed]

42. Marei MK, Saad MM, El-Ashwah AM, Ei-Backly RM, Al-Khodary MA. Experimental formation of periodontal structure around titanium implants utilizing bone marrow mesenchymal stem cells: A pilot study. J Oral Implantol. 2009;35:106-29. [PubMed]

43. Langenbach F, Naujoks C, Kersten-Thiele PV, Berr K, Depprich RA, Kübler NR, et al. Osteogenic differentiation influences stem cell migration out of scaffold-free microspheres. Tissue Eng Part A. 2010;16:759-66. [PubMed]

44. Nishino Y, Yamada Y, Ebisawa K, Nakamura S, Okabe K, Umemura E, et al. Stem cells from human exfoliated deciduous teeth (SHED) enhance wound healing and the possibility of novel cell therapy. Cytotherapy. 2011;13:598-605. [PubMed]

45. Sumita Mishra: Stem Cells: A Step Ahead in Regenerative Dentistry with Accent on Orthodontics: British Journal of Medicine \& Medical Research 14(12): 1-7, 2016,

46. G. N. Suma, Madhu Pruthi Arora, and Manisha Lakhanpal : Stem cell therapy: A novel treatment approach for oral mucosal lesions: Journal of Pharmacy \& Bioallied Sciences : Jan-Mar 2015; 7 (1): 2-8

47. El-Menoufy H, Aly LA, Aziz MT, Atta HM, Roshdy NK, Rashed LA, et al. The role of bone marrowderived mesenchymal stem cells in treating formocresol induced oral ulcers in dogs. J Oral Pathol Med.2010;39:281-9. [PubMed]

48. Aziz Aly LA, Menoufy HE, Ragae A, Rashed LA, Sabry D. Adipose stem cells as alternatives for bone marrow mesenchymal stem cells in oral ulcer healing. Int J Stem Cells. 2012;5:104-14.

49. Zhang Q, Nguyen AL, Shi S, Hill C, Wilder-Smith P, Krasieva TB, et al. Three-dimensional spheroid culture of human gingiva-derived mesenchymal stem cells enhances mitigation of chemotherapy-induced oral mucositis. Stem Cells Dev. 2012;21:937-47.[PubMed

50. Vanikar AV, Modi PR, Patel RD, Kanodia KV, Shah VR, Trivedi VB, et al. Hematopoietic stem cell transplantation in autoimmune diseases: The Ahmedabad experience. Transplant Proc. 2007;39:703-8. [PubMed]

51. Vanikar AV, Trivedi HL, Patel RD, Kanodia KV, Modi PR, Shah VR. Allogenic hematopoietic stem cell transplantation in pemphigus vulgaris: A single-center experience. Indian J Dermatol. 2012;57:9-1[PubMed]

52. Sudarshan R, Annigeri R, Vijayabala G. Pathogenesis of oral submucous fibrosis: The past and current concepts. Int J Oral Maxillofac Pathol. 2012;3:27-36.

53. Sankaranarayanan S, Ramachandran C, Padmanabhan J, Manjunath S, Baskar S, Senthil Kumar R, et al. Novel approach in the management of an oral premalignant condition - A case report. J Stem Cells Regen Med. 2007;3:21. [PubMed]

54. Sankaranarayanan S, Kailasam S, Elangovan S, Ravi VR, Sarkar S. Autologous bone marrow concentrate (Mononuclear Stem Cell) therapy in the treatment of oral submucous fibrosis. J Indian Acad Oral Med Radiol. 2013;25:1-4.

55. Srinivas K, Aravinda K, Ratnakar P, Nigam N, Gupta S. Oral lichen planus - Review on etiopathogenesis. Natl J Maxillofac Surg. 2011;2:15-6. [PubMed] 
56. Scully C, Carrozzo M. Oral mucosal disease: Lichen planus. Br J Oral Maxillofac Surg. 2008;46:15-21. [PubMed]

57. Ding G, Wang W, Liu Y, Zhang C, Wang S. Mesenchymal stem cell transplantation: A potential therapy for oral lichen planus. Med Hypotheses. 2011;76:322-4. [PubMed]

58. Rastogi P. Emergence of cancer stem cells in head and neck squamous cell carcinoma: A therapeutic insight with literature review. Dent Res J (Isfahan) 2012;9:239-44. [PubMed]

59. Routray S, Mohanty N. Cancer stem cells accountability in progression of head and neck squamous cell carcinoma: The most recent trends! Mol Biol Int 2014. 2014 375325. [PubMed]

60. Beccheroni A, Lucarelli E, Donati D, Sangiorgi L, Capponcelli S, Gorini M, et al. Recovery of stromal stem cells in bone sarcoma patients after chemotherapy: Implication for cell-based therapy in bone defect reconstruction. Oncol Rep. 2003;10:891-6. [PubMed]

61. Michael Glick : Burket's Textbook of Oral Medicine- $12^{\text {th }}$ edition $: 2015$

62. Edwards RG. Stem cells today: B1. Bone marrow stem cells. Reprod Biomed Online. 2004;9:541-83. [PubMed]

63. Gao Z, Zhang L, Hu J, Sun Y. Mesenchymal stem cells: A potential targeted-delivery vehicle for anti-cancer drug, loaded nanoparticles. Nanomedicine. 2013; 9:174-84. [PubMed]

64. Studeny M, Marini FC, Dembinski JL, Zompetta C, Cabreira-Hansen M, Bekele BN, et al. Mesenchymal stem cells: Potential precursors for tumor stroma and targeted-delivery vehicles for anticancer agents. J Natl Cancer Inst. 2004;96:1593-603. [PubMed]

65. Pringle, Maimetes : Human salivary gland stem cells functionally restore radiation damaged salivary glands : Stem Cells 2016 ; March 34(2) ; 640-52 ( pubmed)

66. Saraswathi K, Gopal Lankupalli AR. Stem cell therapy. J Clin Diagn Res. 2012;6(1): 142-4. 